\title{
Dissertation Titles and Synopses
}

\section{Exercise-Induced Hypoxemia and Pulmonary Diffusing Capacity During Exercise}

by Jill Kristine Brambrink, PhD, Temple University, 2002, 136 pages

Exercise-induced hypoxemia (EIH) and pulmonary diffusing capacity during strenuous exercise in highly trained endurance athletes were examined in this study. Male $(n=15)$ and female $(n=6)$ endurance athletes were divided into 2 groups depending on arterial oxyhemoglobin saturation $\left(\% \mathrm{SaO}_{2}\right)$ following a $\mathrm{VO}_{2 \max }$ test: 1) desaturators (DS) $=\% \mathrm{SaO}_{2} \leq 91 \%$, and 2) nondesaturators $(\mathrm{NDS})=\% \mathrm{SaO}_{2} \geq 92 \%$. Diffusing capacity for carbon monoxide $\left(\mathrm{DL}_{\mathrm{co}}\right)$ was measured using the intrabreath technique at rest and during treadmill exercise at $80 \%, 90 \%$, and $95 \%$ of $\mathrm{VO}_{2 \max }$. $\mathrm{DL}_{\text {co }}$ increased in all subjects from rest to each exercise intensity $(P \leq .05)$. In males, $\mathrm{DL}_{\mathrm{co}}$ was $9 \%$ and $11 \%$ higher, as intensity was increased from $80 \%$ to $90 \%(P=.015)$ and from $80 \%$ to $95 \%$ of $\mathrm{VO}_{2 \max }(P=.029)$, respectively, with no change in $\mathrm{DL}_{\mathrm{co}}$ from $90 \%$ to $95 \%$ of $\mathrm{VO}_{2 \max }(P>.05)$. No differences in $\mathrm{DL}_{\mathrm{co}}$ between exercise intensities $(P$ $>$.05) were observed in the female subjects. Separation of values according to group did not show differences in $\mathrm{DL}_{\mathrm{co}}$ during exercise in males or females $(P>.05)$. However, in males, $\mathrm{V}_{\mathrm{E}} / \mathrm{VO}_{2}$ was $12.1 \%, 11.7 \%$, and $13.5 \%$ lower in the DS than in the NDS at $80 \%, 90 \%$, and $95 \%$ of $\mathrm{VO}_{2 \max }$, respectively $(P<.05)$, and was $11 \%$ lower at $\mathrm{VO}_{2 \max }(P \leq .05)$. Similarly, $\mathrm{P}_{\mathrm{ET}} \mathrm{O}_{2}$ was $4.6 \%$ lower and $\mathrm{P}_{\mathrm{ET}} \mathrm{CO}_{2}$ was $13.2 \%$ higher in the male DS than in the NDS $(P \leq .05)$. For males, $\% \mathrm{SaO}_{2}$ at $\mathrm{VO}_{2 \max }$ was positively related to $\mathrm{V}_{\mathrm{E}}, \mathrm{V}_{\mathrm{E}} / \mathrm{VO}_{2}$, and $\mathrm{P}_{\mathrm{ET}} \mathrm{O}_{2}$ $(r=0.50,0.45$, and 0.46 , respectively; $P \leq .05)$. In contrast, $\% \mathrm{SaO}_{2}$ was inversely related to $\mathrm{P}_{\mathrm{ET}} \mathrm{CO}_{2}(r=$ $-0.63, P \leq .05)$. Similar variations were noted in these ventilatory parameters between DS and NDS female subjects, though differences were not significant. The author suggests that EIH is not due to differences in $\mathrm{DL}_{\mathrm{co}}$ during strenuous exercise, but rather is most likely influenced by ventilatory differences between DS and NDS.

\section{Spatial Configuration of Malaria Risk on the Amazon Frontier: The Hidden Reality Behind Global Analysis}

by Marcia Caldas de Castro, PhD, Princeton University, 2002, 293 pages
This dissertation investigates the interrelationships between macropolitical, social, and economic polices, human migration, agricultural development, and malaria transmission on the Brazilian Amazon frontier. The ultimate goals are to 1) identify the local determinants of malaria transmission and thereby provide the necessary information for the design of more efficient malaria mitigation policies; and 2) establish a spatially explicit methodology for analysis of malaria risk in complex ecosystems on the Amazon frontier. The analysis is focused on the Machadinho Settlement Project, located in the state of Rondonia. Field survey data provide information on health, demographic, economic, social, ecological, behavioral, and agricultural characteristics. Profiles of low and high malaria risk were obtained for each of the 4 years studied and for different levels of spatial aggregation. The results highlighted major variation over time and space and characterized the subtle interface between natural and manmade environments for malaria transmission. They also showed that, as the spatial level of aggregation was refined, more detailed risk profiles were obtained. The risk profile representations facilitated the specification of a set of strategies that should be implemented in colonization projects, targeted in both time and space, for increasing the effectiveness and reducing the costs of malaria mitigation in frontier settlements. Important features of the proposed mitigation strategies include, for example, testing and treatment of settlers for malaria on arrival at new settlement projects (before occupying their plots) and malaria education provided to all settlers in the early stages of the project.

\section{Deforestation and Malaria: Associations Between Vegetation, Vector Ecology, and Malaria Epidemiology in the Peruvian Amazon}

by Amy Yomiko Vittor, $\mathrm{PhD}$, The Johns Hopkins University, 2003, 480 pages

The relationships between land cover and malaria vector larval presence, human biting rates, and human malaria prevalence are explored in this dissertation. Larval Anophelines were collected from bodies of water along $125 \mathrm{~km}$ of transects once every 3 weeks for 12 months. In the larval study, $7.4 \%$ of the bodies of water were positive for $A$ darlingi at least once $(n=90)$. Seventeen species of Anopheles larvae were collected. The presence of $A$ darlingi larvae was positively correlated with 
algae, leaf litter, emergent grasses, the aguaje palm (Mauritia flexuosa), clear water, ponds between 51 and $100 \mathrm{~m}$ in circumference, fish farms, the distance to varillal forest (forest growing on sandy soils), the amount of tall secondary growth, and the amount of impervious surface. It was negatively correlated with current and distance to deep water. In the adult study, 12 species of Anopheles were collected. The mean human biting rate for $A$ darlingi was 3.0/6-h collection night. This biting rate was positively associated with the ambient temperature, the amounts of deep water, tall secondary growth, deforested land, impervious surface, and the months of May through August 2001. It was negatively associated with the amount of forest, the distance to deforested land, a new moon, and the months of February through April 2001. The human malaria study revealed that $1.5 \%$ were infected with Plasmodium falciparum, and that $2.3 \%$ were infected with $P$ vivax. The falciparum malaria infection rate was positively associated with fever, the time of departure to the farm, the presence of a fish farm, the number of years living in the same house, the amount of deep water, the amount of tall secondary growth, and the amount of shrub. It was negatively associated with the amount of deforested land and an elevated house (on stilts). Vivax malaria infection was positively correlated with fever, hunting at night, and exiting the bed net after 6 AM. It was negatively correlated with the amount of forest and the distance to tall secondary growth. Even after adjusting for climate and household variables, the amount of tall secondary growth and shrub was predictive of a consistent positive correlation with vector breeding sites, biting rates, and human malaria infection in environments altered by humans in the study region.

\section{Assessment of the Sustained Use of Insecticide- Treated Bednets on All-Cause Child Mortality in an Area of Intense Perennial Malaria Transmission in Western Kenya}

by Thomas Paul Eisele, PhD, Tulane University, 2003, 69 pages

Insecticide-treated bednets (ITNs) have proven to be a promising and affordable intervention for controlling malaria in endemic areas of sub-Saharan Africa. However, there is concern that acquisition of clinical malaria immunity may be delayed by sustained use of ITN in areas of high malaria transmission, consequently shifting the burden of mortality from younger to older children. There is also concern that the efficacy of ITNs may diminish following sustained use because of the potential of lowered malaria immunity among the target popula- tion. In an effort to address these concerns, monitoring of child mortality using a demographic surveillance system (DSS) was continued for an additional 2 years after ITNs were distributed to control villages at the completion of a 2-year community randomized control trial that assessed the impact of ITNs in an area of intense perennial malaria transmission in western Kenya. All-cause child mortality was assessed among children living in villages where ITN coverage has been sustained for more than 4 years, as well as within villages where ITNs had only recently been introduced within the past 2 years. Additionally, this research aimed to provide an evaluation of the DSS at identifying births and deaths in children younger than 5 years using a 2-sample capturerecapture method. Results provide no evidence of a shift in mortality from younger to older children following sustained ITN coverage in this setting. ITNs were associated with saving approximately 355 postneonatal infants and 468 children 1 to 59 months during the course of the 4-year trial. ITNs were also shown to remain efficacious at reducing all-cause postneonatal infant mortality, and to a lesser extent 1- to 59-month mortality, over the entire course of the trial.

\section{A "World" of Mountaineering: The Transnationality of Mount Everest and Other High Himalayan Spaces (Nepal)}

by Susan Elizabeth Frohlick, PhD, York University (Canada), 2002, 337 pages

This dissertation takes as its focus the highest mountain peaks in the world and examines the cultural processes by which these landscapes are desired, commodified, consumed, and produced through mountaineering practices that take place within and across the border of Nepal. Of primary concern are the linkages between local mountaineering practices and wider social processes as well as participation in Himalayan mountaineering and how it is configured by categories of difference. Multisited ethnography has provided the primary methodology for tracking the dispersed cultural formations of Himalayan mountaineering. The research was carried out over 20 months in 1999 and 2000 in various locales in Nepal and Canada. The main field sites included the Khumbu, Everest Base Camp, and Kathmandu in Nepal and Canmore, Banff, and Vancouver in Canada. It investigates international film festivals and other mountaineering cultural venues and focuses on participants in national and international mountaineering expeditions, those involved in guiding and other mountaineering-related activities, and those who are cultural producers for venues such as mountain film and book festivals. The research ultimately challenges the 
boundaries of Himalayan mountaineering spaces that are drawn and redrawn by actors with different stakes in participation. It shows how various mountaineering subjects

These dissertations are most easily accessed via the ProQuest Digital Dissertations Web site, www.lib.umi. $\mathrm{com} /$ dissertations. Most recent dissertations are available in PDF format for download (in their entirety) free of charge for those readers affiliated with a subscribing university. If an unaffiliated individual wishes to order a dissertation, the full abstract can be viewed at the ProQuest Web site, and the entire document can be purchased bound or unbound for a reasonable fee from at the end of the 20th century are reconfiguring their identities in the context of public fascination with high mountains.

ProQuest. Many thanks are extended to Jonathan Erlen, $\mathrm{PhD}$, medical historian at the University of Pittsburgh School of Medicine, for providing a monthly stream of newly minted dissertations from which to choose for this section.

Prepared by George Rodway, CRNP, MSN University of Pittsburgh 